\title{
Group consumption and product diversity: the case of smoking bans
}

\author{
Renaud FOUCART*
}

December 21, 2016

\begin{abstract}
I study product diversity in presence of search costs and groups of consumers. I find that groups with heterogeneous tastes create a leverage effect on competition, so that a large majority of firms may end up offering a product that corresponds to the taste of the minority. I illustrate this idea with the case of smoking bans in bars and restaurants. When the first nonsmoking restaurants opened, there were few of them with little competition and high market power on nonsmokers. By extracting a large surplus from nonsmokers, nonsmoking restaurants became unattractive to other groups, while smoking restaurants were plenty and competitive, attracting both smokers and mixed groups.
\end{abstract}

\section{Introduction}

This paper is about the impact of group consumption on the efficiency of decentralized markets in the presence of search frictions. I show how the tastes of the majority may be underrepresented in the market if those tastes evolve over time. I illustrate this idea with the case of smoking bans in bars and restaurants. This case is convenient to study as it is a largely debated policy issue that has inspired a large empirical literature. The question of a decentralized market's efficiency in providing product diversity when consumers buy in groups is however much more general. Examples include most social or leisure activities when decisions are taken cooperatively by groups with heterogenous tastes, and where perfect information on the product is not available without exerting some search effort (such as movies, theaters, holidays, etc.).

\footnotetext{
*Humboldt University, Berlin - renaud.foucart@hu-berlin.de. I thank Elena Arias, Loïc Berger, Micael Castanheira, Alexandre de Corniere, Marjorie Gassner, Patrick Legros, Erik Mohlin, Volker Nocke, Martin Peitz, Alexandre Petkovic, Anja Schöttner, Petros Sekeris, Vincent Vannetelbosch and two anonymous referees for helpful comments and suggestions.
} 
The decision to allow smoking or not can be thought of as a problem of horizontal differentiation. Bars and restaurants have to take a decision that affects all consumers in the room. This paper builds on a simple model of sequential search with horizontal diversity, by considering groups of consumers with possibly heterogeneous preferences. Groups form randomly, search together on the market, and can become repeat consumers of a firm they like. The model is thus one of random search with the possibility of being faithful to a restaurant through time. ${ }^{1}$ Instead of a random utility model in the line of Wolinsky (1986) or Anderson and Renault (1999), I consider product diversity as a binary choice to be made by each firm, and show that this is enough for an equilibrium to exist that does not rely on the Diamond (1971) paradox. There are three types of groups: smokers, nonsmokers, and mixed groups (both smokers and nonsmokers). I assume utility to be fully transferable within groups, so that mixed groups are ex ante indifferent between smoking and nonsmoking premises.

I show that, when the norm is to allow smoking, restaurants are competitive and accommodate all types of customers. When the share of nonsmokers becomes high enough, some restaurants may benefit from offering a nonsmoking environment. As there are initially few of them, they are less competitive than the other firms and can extract more surplus from nonsmokers by specializing in them. As nonsmoking restaurants fail to meet the expectations of groups of smokers and mixed groups, smoking restaurants see their demand increase with the share of (specialized) nonsmoking restaurants. This higher demand implies that the equilibrium share of nonsmoking restaurants in the market is much lower than the share of nonsmokers in the population. This result corresponds to the first of the stylized fact from the literature on smoking bans (which I discuss below): in most cases, the market alone supplies very few nonsmoking premises before a ban is enforced, even when a large majority of the population does not smoke. A smoking ban leads to an equilibrium symmetric to the initial "all smoking" world: all firms ban smoking, are therefore competitive and accommodate all types of customers. This implies that mixed groups, who would never have consumed in a specialized nonsmoking restaurant, start finding them attractive.

A second largely discussed stylized fact about smoking bans is that there is no evidence that they reduce the profitability of restaurants. The impact on bars is more contrasted, however, due

\footnotetext{
${ }^{1}$ Repeat consumption is an important feature of the dynamic of my model. In the US, repeat customers make up to 71 percent of sales at quickservice restaurants, 68 percent of sales at fast-casual operations, 64 percent at casualdining establishments, 63 percent at family-dining eateries and 51 percent at fine-dining restaurants (National Restaurant Association's 2013 Restaurant Industry Forecast, source: restaurant.org).
} 
to a likely decrease in employment after the ban. I argue that this can be explained by a certain level of substitution between bars and restaurants. If some consumers have to pick a submarket among the two, and if restaurants are the first submarket to offer some nonsmoking environment, bars specialize mostly in smokers and mixed groups. Because some restaurants are nonsmoking, smokers and mixed groups prefer not to have to search and choose a bar instead. After a smoking ban, groups become indifferent between bars and restaurants so that the number of consumers (but not necessarily the profit) in restaurants increases, while the number of consumers and the profits in bars decrease.

The existence of consumption by non-unitary households has been the subject of a lot of attention. One can refer to Donni and Chiappori (2011) for a recent review, and Gersbach and Haller (2001) and Gersbach and Haller (2011) for a general equilibrium analysis. These papers mostly focus on consumption externalities, decision making within groups, other-regarding preferences and group formation. My specification of group consumption is therefore particularly simple: within a group, going to the restaurant is a public good valued differently by different and fully cooperative members, the groups are exogenously formed, maximize a utilitarian welfare function with identical weight, and I rule out any kind of other-regarding preferences. What I add is imperfect information with search frictions: it is because groups of consumers bear a cost in order to acquire information over products that the market may fail to reflect the tastes of the consumers.

While my model is based on discrete valuations, my results are consistent with what random utility models obtain when studying different categories of goods. In particular, Yang (2013) studies a random utility environment where individual consumers want to buy a specific category and search randomly among an imperfect sample of firms. The more demanded category is therefore more competitive in equilibrium, as it is easier to find, giving consumers of this category higher market power. Ex-ante indifferent consumers searching for one category of product would therefore make this category more competitive, and therefore more popular. The difference with my model is that I do not restrict the category a group searches for. And, indeed, at the market equilibrium, I find that nonsmokers go alternatively to smoking and nonsmoking places. The leverage effect of groups could be interpreted as playing a similar role on competition as the one of network externalities in the standard setting literature (see for instance the review by Besen and Farrell, 1994).

Smoking bans are often justified in the public debate by concerns for public health, where 
smoking premises are seen as a negative externality on the population as a whole. ${ }^{2}$ A typical counter argument is that bans go against the freedom of consumers and firms to maximize the gains from trade. The objective of this paper is not to discuss this issue as a tradeoff between health and individual freedom, but to understand the market mechanism described above.

In the next Section, I briefly summarize the relevant facts identified in the literature on smoking bans. In Section 3, I first present the setup of the model and show how differences in tastes allow overcoming the Diamond paradox. I then study how nonsmoking premises may arise coming from a pure smoking world. Section 4 presents the economic impact of a smoking ban and how it can have a differential effect on bars and restaurants. I conclude in section 5.

\section{Stylized facts}

A relatively large literature has focused on the question of smoking bans. Since the earlier stages, it was mostly aimed at estimating the potential impact on the profit of firms, and used by advocates of and opponents to the law. The main economic argument of opponents of bans has been that if individuals and restaurant owners are rational utility maximizers, there is no justification for introducing a law that decides on what the best choice is for individuals. This point is for instance raised by Boyes and Marlow (1996), who argue that a smoking ban can be seen as a way for the majority to receive an income transfer from the minority.

However, the market does not seem to naturally represent the tastes of this majority. Dunham and Marlow (2000) analyze a survey carried out on 600 owners of restaurants randomly chosen in the US. The data shows that only a very small number of restaurants ban smoking (100\% of their seating dedicated to nonsmoking consumers) in states where no smoking ban law has been voted. Moreover, it seems that the share of nonsmoking seating corresponds roughly to the legal obligations, rarely more. In the UK, Adda et al. (2012) find that more than 95\% of the pubs allowed smoking before the ban. In France, the website of the city of Paris (paris.fr) counted slightly more than 100 restaurants or bars offering a hermetic nonsmoking environment (the city counted 12,699 restaurants and bars in 2005) the day before the ban. The existing websites trying to reference nonsmoking restaurants in Brussels (rookvrij.be, thinkabout.be) counted slightly more than 20

\footnotetext{
${ }^{2}$ To take an extreme view Allwright (2004) argues that: 'Given the seriousness of the health consequences of exposure to passive smoke, the economic argument is hardly relevant. For example, would anyone seriously propose that because removing asbestos from buildings costs money and may put marginal businesses out of business, workers should continue to work in dangerously contaminated buildings?'
} 
nonsmoking restaurants or bars in the city (among the more than 3000 referenced by the Belgian institute of statistics) before the smoking ban. The supply of nonsmoking restaurant seats was thus scarce, even if those countries all appear to have a majority of nonsmokers in the adult population. ${ }^{3}$

As for the impact of a smoking ban on the profit of restaurants, among others, positive or non significant impact has been found in El Paso Texas (Huang et al., 2004), in Massachusetts (Bartosch and Pope, 2002), in 15 communities in California and Colorado (Glantz and Smith, 1994), in Flagstaff, Arizona (Sciacca and Ratliff, 1998), or in West Lake Hills, Texas (Huang et al., 1995). ${ }^{4}$ Another approach has been used by Alamar and Glantz (2004). They tested the impact of a 100\% smoking law in two US States (Utah and California). They concluded that there was a slightly positive effect on restaurants' value. Adams and Cotti (2007), in a difference-indifferences analysis for the entire USA, found no significant impact on employment in restaurants.

Two papers undertake separate analysis for bars and restaurants: Phelps (2006) and Adams and Cotti (2007). The variable they study is employment in the considered sector. Both find no significant effect of a ban in restaurants, and a negative effect of a ban in bars. Adams and Cotti (2007, p.5) undertake a separate analysis of bars and restaurants, given that 'Smoking seems to be part of the bar culture and not necessarily part of the restaurant culture'. Dunham and Marlow (2000) argue that it is more difficult to separate smokers and nonsmokers in bars, and that nonsmokers have a lower preference for nonsmoking environment in bars. This difference however does not explain why so few restaurants ban smoking without a ban and why the support increases after the ban. Moreover the 'cultural' argument may be the consequence of the bans and not its cause, as bans have been voted for trains, planes, and many other public places where smoking was part of the 'culture'. Indeed, as emphasized by Adams and Cotti (2007), bars and restaurants are differently affected by bans, but the number of bans is also different. Many bans in

\footnotetext{
${ }^{3}$ Among surveys contemporary to the smoking bans for those countries: $20,9 \%$ of US adults are cigarette smokers (NHIS, 2005), 22\% in the UK (NHS, 2007), 27\% in Belgium (CRIOC, 2004) and 27\% in France (INSEE, 2001)

${ }^{4}$ Dunham and Marlow (2000) and Dunham and Marlow (2003) put those results into perspective, mostly because they do not take into account distributional effects. The authors show that an important percentage of owners (39\%) predicted a decrease in their revenues if a "smoking law" was voted. They argue that the predictions of the owners of restaurants not affected by a smoking regulation did not differ from those of the owners of restaurants affected by the law. A first problem is that they consider as Law States not only those that voted a 100\% smoking ban, but also those who voted laws of regulation (for instance, laws asking the restaurants to have at least some percentage of their seating in nonsmoking zones) or partial smoking bans. Indeed, while looking more carefully at the 32 States defined as Law States, only 3 of them had a $100 \%$ smoking ban on bars and restaurants at the time the study was published. In fact, the only necessary condition to be considered as a Law State is to have voted laws allowing or requiring nonsmoking sections in restaurants. Moreover, the question that has been asked refers to expected variation of profit if a smoking law is voted, without defining precisely what kind of ban or restriction is considered, allowing the owners to implicitly interpret this regarding the kind of law they face or fear to face.
} 
bars are implemented when a ban is already enforced in restaurants. And many jurisdictions still ban smoking only in restaurants. What I show in this paper is that, even with identical preference parameters in both submarkets, a smoking ban can still have a differential effect.

\section{The model}

Restaurants consist in a continuum of sellers of mass 1 offering a single product in an either smoking or nonsmoking environment, with marginal production cost of zero. Restaurants exist in perpetuity. Consumers are a continuum of groups of mass 1 with heterogeneous preferences towards the smoking environment.

\subsection{The consumer problem}

At every period, a mass $\tau$ of new groups, each of them composed of two consumers, enters the market, while each already existing group is dissolved with probability $\tau$, so that there is a steadystate continuum of mass 1 of active groups. A share $\alpha$ are groups of nonsmokers $(n s), \mu$ are mixed groups $(m)$ and $1-\mu-\alpha$ are smokers $(s)$, with $\alpha, \mu$ and $1-\alpha-\mu>0$. A group of type $i \in\{n s, m, s\}$ has tastes described by a per-period conditional utility function (net of any search cost) of the form

$$
u_{i}^{j}\left(p_{j}\right)=v_{i}^{\sigma_{j}}-p_{j}
$$

if it buys from a restaurant $j$ with smoking policy $\sigma_{j} \in\{N S, S\}$, "non smoking" or "smoking", and price $p_{j}$. The taste parameter $v_{i}^{\sigma_{j}}$ can be interpreted as a match value between the smoking policy of a restaurant and the taste of a group. When policy and taste coincide, the match value is $v_{n s}^{N S}=v_{s}^{S}=V>0$; when it does not, the value is $v_{s}^{N S}=v_{n s}^{S}=v \in(0, V)$; the average in a mixed group is $v_{m}^{S}=v_{m}^{N S}=\frac{v+V}{2}$, regardless of the restaurant. The interpretation of the price is one of a "profit margin," as restaurants choose the quality they provide together with their price. For this reason, while consumers know the distribution of prices, they have to experience a restaurant in order to know its individual price. I only consider symmetric equilibria in the sense that firms setting an identical smoking policy charge the same price. In order to simplify the notation, I denote by "restaurant of type $j \in\{N S, S\}$ " a restaurant with smoking policy $\sigma_{j}$. 
The idea is that groups need to experience in order to find their "favorite" restaurant, where they become repeat consumers. Upon entering the market, a group is first randomly matched with a restaurant, observes its price and smoking policy, and decides whether or not to eat there. I assume groups have an outside option normalized to zero, so that at each period a group $i$ matched with a restaurant $j$ accepts an offer and eats there if and only if

$$
u_{i}^{j}\left(p_{j}\right) \geq 0
$$

Regardless of that decision, the group decides to go back to that restaurant for the next period, or to (randomly) select a new restaurant next time, after having paid a search cost $s>0$. One can think of this cost as the necessary energy it takes to agree on a new restaurant within a group. While doing so, the group knows the match values as well as the distribution of prices and smoking policy, with $\gamma$ the share of nonsmoking restaurants on the market. While I allow restaurants to modify their price and smoking policies, I focus on equilibria where $p_{N S}, p_{S}$ and $\gamma$ remain constant through time. The search decision is thus a mapping between the group type $i$, the match firm type $\sigma_{j} \in\{N S, S\}$ and price $p_{j}$, and the state of the economy $\left\{p_{S}, p_{N S}, \gamma\right\}$. The state of the economy is common knowledge. A group searches if the continuation value of search is higher than the continuation value of staying at the same restaurant.

The continuation value of a group of type $i$ searching until it finds a nonsmoking restaurant is

$$
W=-s+\gamma \frac{u_{i}^{N S}}{\tau}+(1-\gamma)\left(\max \left\{0 ; u_{i}^{S}\right\}+(1-\tau) W\right)
$$

The group bears a linear search cost $s$ for trying a new restaurant. With probability $\gamma$, this restaurant bans smoking, and the group stays there until it is dissolved, while with probability $1-\gamma$, it allows smoking, and the consumer either buys there or refuses the offer (as from equation (2)), before searching again if it survives the next period (with probability $1-\tau$ ). A group prefers to search for a nonsmoking restaurant whenever $W \geq \frac{\max \left\{0 ; u_{i}^{S}\right\}}{\tau}$. Using expression (3), this simplifies to

$$
u_{i}^{N S} \geq \max \left\{0 ; u_{i}^{S}\right\}+\frac{\tau s}{\gamma}
$$

Because of the random rate of dissolution $\tau$, each group knows it will meet on average a number $\frac{1}{\tau}$ of time. Hence, the lower the value of $\tau$, the higher the incentives to find a good match. A group 
also has higher incentives to search when search costs are low and the share of restaurants with their preferred smoking policy is high. Defining an expression symmetric to (3), one can derive that a group prefers to search for a smoking restaurant whenever

$$
u_{i}^{S} \geq \max \left\{0 ; u_{i}^{N S}\right\}+\frac{\tau S}{1-\gamma}
$$

\subsection{The restaurant problem}

The objective of a restaurant $j$ is to maximize its expected per-period profit $\pi_{j}$. The strategy of a restaurant is a function from a state of the economy $\left\{p_{S}, p_{N S}, \gamma\right\}$ to $\{p, \sigma\}$, with $p \geq 0$ and $\sigma \in\{S, N S\}$.

I focus on Markovian Nash equilibria, in the sense that the strategies of restaurants only condition on the state of the economy $\left\{p_{S}, p_{N S}, \gamma\right\}$. The state of the economy is the only payoff-relevant variable as it directly determines the search behavior of consumers and the average market share of each type of restaurant. ${ }^{5}$ As each firm is atomless, firms best respond to the aggregate state of the economy, not to the specific strategy of every individual firm. An equilibrium is a situation in which no restaurant is strictly better off by modifying its strategy, so that $\left\{p_{S}, p_{N S}, \gamma\right\}$ remain constant through time. Hence, a strategy profile $\left(p_{j}, \sigma_{j}\right)$ is an equilibrium if for every restaurant $j$, it holds that

$$
\pi_{j}\left(p_{j}, \sigma_{j}, p_{S}, p_{N S}, \gamma\right)=\max _{p \geq 0, \sigma \in\{S, N S\}} \pi_{j}\left(p, \sigma, p_{S}, p_{N S}, \gamma\right)
$$

Using (4) and (5), it is possible for a seller, choosing smoking policy $\sigma_{j} \in\{N S, S\}$ and setting price $p_{j}$, to perfectly determine her expected demand given a constant state of the economy $\left\{p_{N S}, p_{S}, \gamma\right\}$

I first show how, in a world with an overwhelming majority of smokers, the presence of heterogeneous consumers is enough for an equilibrium not driven by the Diamond paradox to exist (and to be more realistic than the Diamond paradox). Then, I show how the transition from a world where a majority of groups are smokers and all restaurants allow smoking to an equilibrium with a majority of nonsmoking groups and product diversity is possible. In this equilibrium, all groups

\footnotetext{
${ }^{5}$ This assumption is not important when I focus on the conditions of existence of equilibria with constant state of the economy, but matters when considering dynamic transitions, as I do not allow for "complex "bootstrapping" in which each player conditions on a particular variable only because others do the same." (Maskin and Tirole, 2001, p.193)
} 
but nonsmokers go to smoking restaurants.

\subsection{Benchmark: decentralized equilibrium in a "smoking" world}

The objective of this subsection is to show how consumers' heterogeneity is sufficient for the existence of a "low price" equilibrium, even with an overwhelming majority of smokers. I start by assuming there is a large majority of smokers so that $1-\alpha-\mu>\alpha$, with $(1-\alpha-\mu) V>$ $\max \left\{\frac{(\alpha+\mu)(V+v)}{2}, v\right\}$. This aims at representing most industrialized countries at the end of the second world war, with for instance more than $80 \%$ of the male adult population smoking in the UK in $1948 .^{6}$

Lemma 1 A monopolistic restaurant allows smoking and sets price $p=V$, if $(1-\alpha-\mu) V>$ $\max \left\{v,(1-\alpha) \frac{v+V}{2}\right\}$.

The formal proof is in Appendix. A monopolistic restaurant sets a single price in order to maximize its expected profit. Hence, if extracting the full surplus of smokers while not serving the others yields higher profit than serving all customers, the monopolist chooses a high-price smoking environment.

Because of the presence of search costs, this monopoly price is also an equilibrium with a continuum of players. The argument is the standard Diamond paradox. If all firms offer a price $p=V$, a single firm decreasing its price is not enough to make consumers search. Hence, it can at most get surplus $\pi=v$ by lowering its price. I show in the following proposition that, because of the heterogeneity of consumers tastes, this "Diamond equilibrium" coexists with a lower price equilibrium $p=v$ when search costs are sufficiently small, and groups stay for a sufficiently large number of periods in the market.

Proposition 1 Assume all restaurants allow smoking. There exists a market equilibrium with $p=v$ for all restaurants, if and only if search costs are low enough (i.e, $\left.s \leq \frac{\alpha v}{(1-\alpha) \tau}\right)$ and groups are not dissolved too often (i.e, $\tau \leq \frac{v}{(1-\alpha) V}$ ).

The formal proof is in Appendix. In this non-Diamond equilibrium, all firms offer a smoking environment at a price sufficiently low for all groups to get positive surplus. The reason is that

\footnotetext{
${ }^{6}$ Source: Cancer Research UK, Smoking Prevalence: 1948-2012, http://www.cancerresearchuk.org/ accessed August 2015 .
} 
a marginal price increase above the one that makes nonsmokers indifferent leads to a discreetly smaller demand. Hence, no firm ever has an incentive to set a price slightly above the equilibrium one. There are however two conditions for this equilibrium to hold. The first one is that there is no discrete increase in the price that allows keeping all but the nonsmoking customers and increase expected profit. This is the case if search costs are sufficiently low, so that all groups react to such a price increase by searching for another restaurant the next time. The second is that groups are not dissolved too often, so that it is not profitable for restaurants to specialize in "ripping off" one-time consumers by extracting their entire surplus.

It is not only true that consumer heterogeneity allows for a non-Diamond equilibrium. It is also the case that this low-price equilibrium is more robust. At the low-price equilibrium, a coordinated change of strategy by a small number of firms setting a high price is not enough to switch to the Diamond equilibrium. The reverse is not true. As long as a sufficiently high share $\lambda \geq \lambda^{\prime}$ of firms are allowed to simultaneously revise their policy, they could set a price $p=v$ together, so that consumers start searching, and those firms make higher profit than the high-price ones under the conditions defined in Proposition 1. The continued value of staying at a high-price firm is zero. Hence, the minimum share $\lambda^{\prime}$ of "deviators" is such that $\lambda \frac{V-v}{\tau} \geq s$. This rewrites:

$$
\lambda \geq \frac{s \tau}{V-v}=\lambda^{\prime}
$$

The threshold value $\lambda^{\prime}$ is getting smaller and smaller as search costs decrease.

As indoor smoking only became a concern in the early 1990s, I study the transition from a world where all firms offer a smoking environment at low price, as described in Proposition 1.

\subsection{A market for nonsmoking restaurants}

The objective of this subsection is to study how, departing from a state of the world where all firms allow smoking, the market can supply nonsmoking premises.

I assume an initial state of the world where all firms allow smoking at low price, $\gamma=0$ and $p_{S}=v$, corresponding to Proposition 1. I study best responses to this state of the world when the share of nonsmoking groups unexpectedly and permanently increases. Because restaurants maximize their expected per-period profit without discounting the future, firms maximize their 
profit given the new share of nonsmoking groups $\alpha .^{7}$ The revision procedure is the following: at every period, a share $\lambda$ (possibly very small) of the restaurants is allowed to modify (at no cost) their price and smoking policy if it increases their expected per-period profit given the state of the world $\left\{p_{S}, p_{N S}, \gamma\right\}$. The following Proposition shows that an equilibrium with a strictly positive share of nonsmoking restaurants serving only nonsmoking groups exists when $\alpha V>v$, and that this equilibrium derives from a sequence of best responses to the state of the world where $\gamma=0$ and $p_{S}=v$.

Proposition 2 There exists an equilibrium in which a share $\gamma^{*}=\max \left\{0, \frac{\alpha V-v}{(1-\tau) \alpha(V-v)}\right\}$ of restaurants offer a nonsmoking environment at high price $p_{N S}=V$, patronized by nonsmokers only, while all other consumers search for a smoking environment, offered at price $p_{S}=v$. Nonsmoking groups also occasionally visit smoking restaurants. This equilibrium exists whenever groups are not dissolved too often, $\tau \leq \frac{(1-\alpha) v}{\mu(V+v)}$, search costs are sufficiently low, $s \leq\left(1-\gamma^{*}\right) \frac{V+v}{2 \tau}$, and the conditions of existence in Proposition 1 are fulfilled. A strictly positive share of nonsmoking restaurants $\gamma>0$ operates in equilibrium if and only if $\alpha V>v$. This equilibrium is reached from a sequence of firms' best responses to a state of the world where $\left\{p_{s}=v, \gamma=0\right\}$.

In such a configuration, smoking restaurants are the mainstream choice, as they set a price sufficiently low for all types of groups to eat there. Nonsmoking restaurants are a niche product, as they specialize in nonsmoking consumers only. Because of that, they can charge a very high price and extract the entire surplus of the consumers with the highest valuation for their product. This explains why the share of nonsmoking premises can be much lower than the share of nonsmoking consumers in the population, as both mixed groups and smokers prefer to search until they find a smoking environment. The first specific condition for this equilibrium to exist is that groups are not dissolved too often. If it were the case, nonsmoking restaurants could benefit from setting an intermediary price and extracting the entire surplus of one-time-only mixed groups of customers. Such restaurants could exist for instance in touristic places with little chance that consumers return. The second condition is that search costs are sufficiently low, and the share of smoking restaurants sufficiently high, for mixed groups and smokers to benefit from searching.

This equilibrium is naturally reached from a sequence of firms' best responses to a state of

\footnotetext{
${ }^{7}$ While discounting would have been more realistic, my specification ensures that the small number of restaurants switching to a nonsmoking environment is not driven by costs of adaptation. In the absence of discounting, if the change in $\alpha$ is expected, firms simply anticipate the change, which only affects the timing of the transition.
} 
the world where all firms allow smoking at low cost (as in Proposition 1). When nonsmoking groups become an important share of the population, some restaurants benefit from offering a specialized nonsmoking environment. By doing so, the profit of all other restaurants increases, as nonsmoking restaurants only attract a small share of the demand. The equilibrium is reached when nonsmoking restaurants, extracting the entire surplus of the nonsmoking groups patronizing them, have an expected profit identical to the one of smoking restaurants.

In Proposition 2, nonsmokers sometimes buy from nonsmoking restaurants, but are indifferent between those and the smoking ones, as $u_{n s}^{N S}=u_{n s}^{S}=0$. For this reason, this equilibrium structure is robust to advertisement of restaurants' smoking policy. Indeed, while a restaurant cannot perfectly advertise its quality, it can be argued that restaurants are able to clearly advertise whether they allow smoking or not. Assume groups could choose to bear a strictly positive search cost $c$ (possibly very low) before entering the market, to be matched only with a certain category of restaurants. Both smoking and mixed groups would choose to search only among smoking restaurants (as $u_{s}^{S}>u_{s}^{N S}$ and $\left.u_{m}^{S}>u_{m}^{N S}\right)$. Nonsmoking groups would not pay, since they are indifferent between the two types of restaurants. In this case, the equilibrium share of nonsmoking restaurants would be even lower, $\gamma^{*}=\frac{\alpha V-v}{\alpha(V-v)}$, which is equivalent to the share when $\tau \rightarrow 0$. No restaurant however has any incentive to change its price, as smoking restaurants still serve all types of customers and nonsmoking restaurants still serve only nonsmokers.

The equilibrium described in Proposition 2 is not unique. In the online Appendix, I characterize all possible equilibria. I restrict my attention here on those satisfying the following criteria: (i) they hold when search costs become very low (i.e. $s \rightarrow 0$ ), (ii) they are stable in the sense that best responses to a small perturbation in $\gamma$ bring firms back to the proposed equilibrium, (iii) they are robust to advertising of the smoking policy of restaurants and (iv) they are robust to a (self-enforcing) coordinated deviation by a small share of restaurants. For instance, when the "Diamond" equilibrium where every restaurant offers a nonsmoking environment at a high price exists, it is not robust to the advertisement of the smoking policy, as even atomless firms could increase their profit by revising their policy and allowing smoking at low price. As shown after Proposition 1, it is not robust either to a deviation by a small share $\lambda$ of the restaurants to a lower price when search costs are low. The said deviation is self-enforcing in the sense that coordination is enough to sustain it without commitment.

Besides the equilibrium described in Proposition 2, two other ones satisfy the conditions under- 
lined above. The second equilibrium holds under conditions symmetric to the ones of Proposition 2 , if the share of smoking groups is sufficiently high. In this equilibrium, nonsmoking restaurants offer the low price and smoking restaurants offer the high price. It can be reached from a sequence of best responses to a state of the world $\left\{p_{N S}=v, \gamma=1\right\}$. Hence, if the consequence of a smoking ban is that all firms offer a nonsmoking environment at a low price, repealing the smoking ban should lead to an equilibrium where none or few firms allow smoking and specialize in smoking groups.

Switching from a world with $\left\{p_{S}=v, p_{N S}=V, \gamma^{*}\right\}$, with $\tau$ and $s$ sufficiently small, to a different equilibrium would however need a much larger coordination of restaurants. First, smoking restaurants never increase their profit by modifying their price as long as there is a positive mass of smoking restaurants setting a price $p_{s}=v$,

$$
\pi_{S}=\alpha v+\frac{(1-\alpha) v}{1-\gamma(1-\tau)}=\max _{p \geq 0} \pi_{j}\left(p, \sigma_{j}=S, p_{S}=v, p_{N S}=V, \gamma\right), \forall \gamma<1
$$

This means that as long as smoking and mixed groups search for a smoking restaurant at price $v$, a restaurant has too much to lose by increasing its price.

Second, it is never a best response for a nonsmoking restaurant to set a price different from $V$ as long as smoking restaurants offer a price $v$,

$$
\pi_{N S}=\alpha V=\max _{p \geq 0} \pi_{j}\left(p, \sigma_{j}=N S, p_{S}=v, p_{N S}=V, \gamma\right), \forall \gamma<1
$$

The third equilibrium satisfying the conditions described above involves symmetric prices, with $\left\{p_{S}=p_{N S}=\frac{v+V}{2}, \gamma \in(0,1)\right\}$. Both smokers and nonsmokers search until they find the right match, while mixed groups are indifferent. On the one hand, consumers benefit from higher quality matches. On the other hand, they also face higher prices, as restaurants extract the entire surplus of mixed groups. Reaching this equilibrium from a sequence of deviations to one of the two others would need a coordination of all restaurants, a public intervention, or a large coordination of consumers purposely choosing (and committing to) a search behavior not maximizing their expected payoff.

Note that I assume utility to be fully transferable within groups. Assuming a certain degree of nontransferabilities would make the conditions of existence of the equilibrium described in 


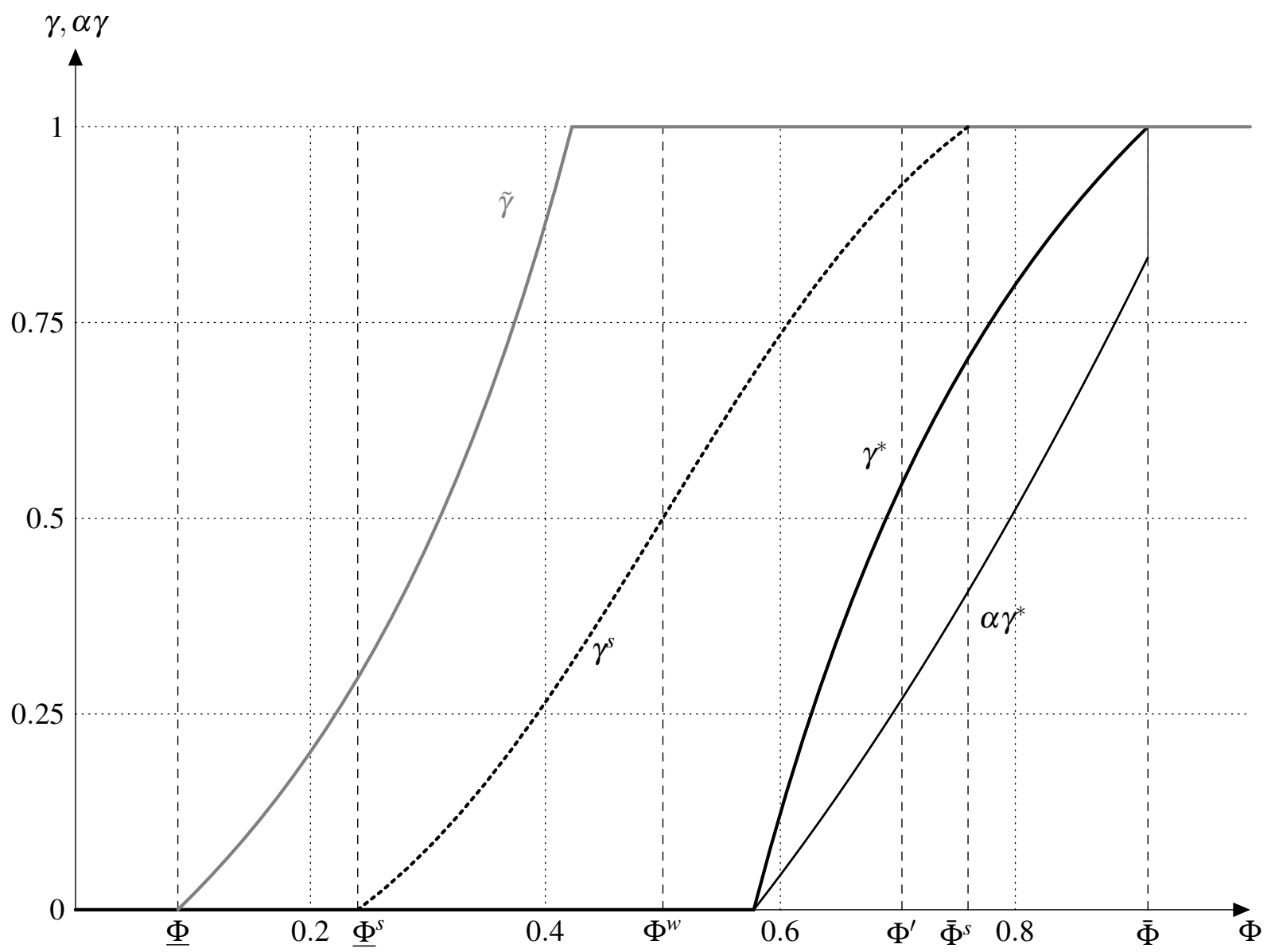

Figure 1: Equilibrium share of $\gamma^{*}$ for $s \rightarrow 0, \tau=0.1, V=3$ and $v=1$.

Proposition 2 easier to meet, because it would be more difficult for a nonsmoking restaurant to meet the participation constraint of a mixed group. For instance, with fully non-transferable utility, a mixed group would refuse any offer whenever $p>v$.

The share of nonsmoking restaurants $\gamma^{*}$ resulting from Proposition 2 can be relatively low. Figure 1 plots this supply of nonsmoking restaurants with respect to the share of nonsmokers for parameter values $V=3, v=1, \tau=0.1$ and the linear search cost $s$ sufficiently small $(s \rightarrow 0)$. For simplicity, I assume that pairs of consumers are randomly composed, so that a share $\Phi$ of nonsmokers in the population yields $\alpha=\Phi^{2}$, and $(1-\alpha-\mu)=(1-\Phi)^{2}$. This is obviously an arbitrary assumption as, for instance, groups may be formed by affinity (including smoking preferences) and groups are not always composed of two people. The parameter values are chosen in order for shares of nonsmokers corresponding to the actual prevalence of smoking among adults - between 20 and $30 \%$ in most developed countries - to yield a strictly positive supply of nonsmoking premises. For these parameter values, the first nonsmoking restaurants start to open 
when $\Phi \approx 0.58$, corresponding to the smoking prevalence in the late seventies in the $\mathrm{UK}^{8}$ and the late sixties in the US. ${ }^{9}$ The equilibrium share of nonsmoking restaurant $\gamma^{*}$ does not correspond to the share of consumers going to nonsmoking restaurants (this share is given by the curve $\alpha \gamma^{*}$ ). As smoking restaurants are more populated, the share of customers going to a nonsmoking restaurant remains low even for a very low prevalence of smoking in the population.

The equilibrium described in Proposition 2 exists for all $\Phi<\bar{\Phi}$. For any state of the world $\left\{p_{S}=v, p_{N S}=V, \gamma>\gamma^{*}\right\}$

$$
\pi_{j}\left(p=v, \sigma=S, p_{S}, p_{N S}, \gamma\right)=\max _{p \geq 0, \sigma \in\{S, N S\}} \pi_{j}\left(p, \sigma, p_{S}, p_{N S}, \gamma\right)
$$

so that when there are more than the equilibrium share of nonsmoking restaurants, firms maximize their profits by revising their smoking policy and offering a smoking environment at low price. This corresponds to the area above the curve $\gamma^{*}$ in Figure $1 .{ }^{10}$ Similarly, below the curve, firms allowed to revise their policy maximize their profit by banning smoking and setting a price $p_{N S}=$ $V$. Hence, when most consumers smoke, there exists an equilibrium where $\left\{p_{S}=v, \gamma=0\right\}$ and no restaurant wants to revise its policy. If the share of nonsmokers discretely and unexpectedly increases to a higher value, restaurants revise their policy to switch to a high price nonsmoking restaurant until $\gamma=\gamma^{*}$.

The vertical dashed line at $\bar{\Phi}$ corresponds to the point where the equilibrium does not exist anymore given that all restaurants ban smoking. In the area to the right of this line, a strictly positive share of nonsmoking restaurants could increase their profit by setting a low price $v$, hence converging to a state of the world with $\left\{p_{N S}=v, \gamma=1\right\}$. From that state of the world, smoking restaurants would only open (setting $p_{S}=V$ ) if the share of smoking groups become very large. The share of nonsmoking restaurants in this symmetric equilibrium $\tilde{\gamma}$ is represented by the gray line. This equilibrium does not exist if there are too few nonsmokers (low values of $\Phi$ ), corresponding to the area to the left of $\underline{\Phi}$. Hence, for values of $\Phi \in(\underline{\Phi}, \bar{\Phi})$, the game displays multiple equilibria satisfying the criteria described above, while the equilibrium is unique for the most extreme values of

\footnotetext{
${ }^{8}$ Smoking prevalence in the overall population was of $45 \%$ in 1974 and $40 \%$ in 1978 according to the UK office for National Statistics General Lifestyle Survey data, http://www.ons.gov.uk, accessed September 2015.

${ }^{9}$ Smoking prevalence in the overall population was of $42.4 \%$ in 1965 and $37.4 \%$ on 1970 in the US according to the US centers for Disease Control and Prevention, www.cdc.gov, accessed September 2015.

${ }^{10} \mathrm{~A}$ similar result would be reached if firms best-respond to a perfectly-anticipated path to the equilibrium, as they are indifferent between the two smoking policies at equilibrium but enjoy a temporary benefit from the higher profit obtained by switching before the equilibrium $\gamma^{*}$ is eventually reached.
} 
$\Phi$. Finally, the vertical dashed line at $\Phi^{w}=0.5$ represents the point at which a smoking ban starts increasing aggregate consumer welfare, as compared to the equilibrium described in Proposition 2 (see the computations in Section 4.1).

For the considered parameter values, a third equilibrium also exists (see above and online Appendix), with $p_{S}=p_{N S}=\frac{v+V}{2}$ and $\gamma^{s} \in(0,1)$. It cannot be reached from a sequence of best responses to any of the two other equilibria. It is represented by the dotted curve $\gamma^{s}$, and exists for $\Phi \in\left(\underline{\Phi}^{s}, \bar{\Phi}^{s}\right)$. For the values of $\Phi$ comprised between $\Phi^{\prime}$ and $\bar{\Phi}^{s}$, it would yield a higher aggregate consumer surplus than the one described in Proposition 2. This equilibrium indeed treats better the nonsmokers at the cost of treating all the other groups worse. It does however never provide higher consumer surplus than both the equilibrium of Proposition 2 and a smoking ban at the same time.

The intuition behind the price structure in Proposition 2 does not derive from the particular setup where firms price exactly at the participation constraint of a certain category of consumers. It simply reflects the difference in the outside option consumers have if they search in the market. Assume now that consumers also have some random preference for restaurants. If most restaurants allow smoking, the few first nonsmoking ones have a relatively high market power on their nonsmoking patrons. They are aware that the supply of nonsmoking firms is low, and that nonsmoking consumers would have to search extensively for a better deal. As the supply of nonsmoking premises is lower, so is competition in this sector. Nonsmoking restaurants set a higher price, which reduces the share of the customers they attract. In particular, mixed groups - ex ante indifferent between smoking and nonsmoking premises - find much better deals in smoking restaurants, as this market is more competitive. Therefore, smoking restaurants remain highly competitive and attract most consumers, while nonsmoking restaurants become specialized in nonsmokers.

The results from this section are an attempt to answer the first stylized fact on the market for nonsmoking restaurants: even when the number of nonsmokers is high, there may only be a scarce supply of nonsmoking premises. Coming from a world where all restaurants allow smoking, being among the first ones to ban smoking gives a high market power on nonsmoking consumers. This market power increases firm's profits when switching to a nonsmoking environment, but also the profits of the other firms, as all groups but the purely nonsmokers search until they find a place that allows smoking.

In the next section, I compare the market outcome with and without a smoking ban in order to 
understand the second stylized fact.

\section{On the economic impact of smoking bans}

In this section, I compare the equilibrium studied in Proposition 2 to the one in the presence of a ban. I first consider a ban in restaurants. Second, I assume that bars and restaurants are substitutes for a fraction of the groups. I then show that this may explain the second stylized fact: restaurants may see their profit increase after a smoking ban if the share of nonsmoking restaurants is higher than the share of nonsmoking bars in the market equilibrium. In that case, before the ban, mixed groups that are ex ante indifferent between bars and restaurants choose bars, in order to bear a lower expected search cost. The behavior of mixed groups is self-fulfilling: by going to bars, they make the bars more attractive to them. After the ban, they return to being indifferent between bars and restaurants and therefore patronize restaurants more. This explains why bars may lose consumers from the market being homogenized.

\subsection{A smoking ban in restaurants}

A law that totally bans smoking in restaurants brings us back to a world with homogenous supply as studied in Proposition 1, but with only nonsmoking premises.

Lemma 2 In the presence of a smoking ban, a low price equilibrium $\left\{\gamma=1, p_{N S}=v\right\}$ exists if and only if $s \leq \frac{(1-\alpha-\mu) v}{(\alpha+\mu) \tau}$ and $\tau \leq \frac{v}{(\alpha+\mu) V}$.

Proof. Identical to the proof of Proposition 1, with the share of nonsmoking groups $\alpha$ instead of the share of smoking groups $1-\alpha-\mu$.

For the same reason as in Section 3.3, this equilibrium coexists with a less robust "Diamond" equilibrium where only nonsmokers are served at a high price. Assuming a smoking ban, from a world with some nonsmoking restaurants (as described in Proposition 2) to a world with a smoking ban and low price, we can compute the changes in welfare for different consumer types.

Proposition 3 Compared to a market equilibrium $\left\{p_{S}=v, p_{N S}=V, \gamma=\gamma^{*}\right\}$ a smoking ban $\left\{p_{N S}=\right.$ $v, \gamma=1\}$ 
- Increases the expected surplus of a nonsmoking group by an amount $\Delta_{n s}=\frac{V-v}{\tau}$.

- Increases the expected surplus of a mixed group by an amount $\Delta_{m}=\frac{\gamma^{*}(V-v+2(1-\tau) s)}{2\left(1-\gamma^{*}(1-\tau)\right)}$.

- Decreases the expected surplus of a smoking group by an amount $\Delta_{s}=\frac{\left(1-\gamma^{*}\right) \frac{(V-v)}{\tau}-\gamma^{*}(1-\tau) s}{\tau\left(1-\gamma^{*}(1-\tau)\right)}$.

The formal proof is provided in Appendix. Nonsmoking groups are unambiguously better off. Before the ban they received zero surplus, while after the ban they get their favorite restaurant at a low price and without searching. The mixed groups are ex ante indifferent between smoking and nonsmoking premises. However, the smoking ban makes their life simpler, because they do not have to search on the market. Thus, a smoking ban increases their surplus proportionally to the loss of surplus they had by postponing their consumption and paying search costs in the presence of two types of restaurants. Finally, smokers are worse off, but their loss also depends on how much they had to search before the ban.

The gains from a smoking ban depend on how popular nonsmoking restaurants were before. If there were many of them, the ban does not decrease the surplus of smokers a lot, but increases the surplus of mixed groups. If the supply of nonsmoking restaurants was scarce, the gain in terms of search costs for mixed groups is moderate, while the loss for smokers is high. The values of the differentials in utility $\Delta$ as a function of $\alpha$ (and therefore $\Phi$, by assuming $\Phi=\alpha^{2}$ ) are provided in the proof of Proposition 3 in Appendix. Note that in the presence of advertising of smoking policy, they converge to $\Delta_{n s}=-\Delta s$ and $\Delta_{m}=0$ when the cost $c$ of searching only among a certain type of restaurants decreases.

The analysis of the impact of the smoking ban may also help understanding why the support for smoking bans typically increases after a smoking ban has been enacted (see Gilpin et al., 2004; Borland et al., 2006; Fong et al., 2006; Gallus et al., 2006). Before a ban, the only experience mixed groups have of nonsmoking restaurants is either nonexistent or problematic (because it is never profitable to go to a nonsmoking restaurant with smokers). If before a ban some nonsmokers either expect it will become more difficult to go out with smokers or that their favourite smoking place will offer a value for money as low as the nonsmoking places they know, they may oppose a smoking ban ex-ante, but change their mind after observing that all consumers continue to go out after the ban. 


\subsection{A smoking ban in bars and restaurants}

The objective of this subsection is to understand the second stylized fact: why smoking bans may have an undetermined effect on the restaurants' profit and a negative effect on bars. Assume that two separate submarkets coexist with a given degree of substitutability. On the supply side, restaurants and bars are both a continuum of mass 1 . On the demand side, there is a continuum of mass 1 of consumers patronizing bars, a continuum mass 1 of consumers patronizing restaurants, and a continuum of mass $\Omega$ of "good timers", ex ante indifferent between bars and restaurants. All groups have identical parameters $\alpha, v, V, \tau$ and $s$. "Good timers" have to choose whether they want to go to a bar or a restaurant before entering the market.

Assumption 1 Before entering the market, a group of "good timers" chooses the submarket that maximizes its joint expected payoff.

In consequence, the following decision rule for "good timers" follows:

Lemma 3 Denote by $\gamma_{r}$ and $\gamma_{b}$ the respective shares of nonsmoking restaurants and bars, and assume the equilibrium structure is the one described in Proposition 2. Under Assumption 1, the respective choices of the three different groups of "good timers" are such that:

- Nonsmokers are indifferent,

- Smokers and mixed groups choose submarket $i \in\{r, b\}$, with i determined by $\gamma_{i}=\min \left(\gamma_{r}, \gamma_{b}\right)$.

Proof. Nonsmokers are indifferent as their surplus is independent of $\gamma_{i}$. Mixed groups and smoking groups have an expected payoff strictly decreasing in $\gamma_{i}$.

The decision rule is such that all groups but the nonsmoking ones prefer the market with fewer nonsmoking premises, as it decreases the expected search cost they have to bear. As a tie-breaking rule, I assume groups choose the two markets with equal probability when indifferent. The choice of the "good timers" has a non-neutral effect on the value of $\gamma_{i}$. Indeed, assume restaurants were the first ones to offer a strictly positive number of nonsmoking environments. A reason could be that different regulations applied to them, which gave incentives to the first restaurants to ban smoking. Another is that at some point in history the share of nonsmokers was more prevalent 
in the population of restaurants patrons. All "good timers" but the nonsmoking groups therefore patronize bars and nonsmoking "good timers" randomize.

The equilibrium share of nonsmoking restaurants is strictly increasing in $\Omega$, as it is given by equating the expected profits of smoking and nonsmoking restaurants,

$$
\alpha\left(1+\frac{\Omega}{2}\right) V=\alpha\left(1+\frac{\Omega}{2}\right) v+\frac{(1-\alpha) v}{1-\gamma_{r}(1-\tau)}
$$

so that $\gamma_{r}^{*}=\frac{(\alpha V-v)+\frac{\alpha \Omega}{2}(V-v)}{(1-\tau) \alpha\left(1+\frac{\Omega}{2}\right)(V-v)}$.

As all "good timers" but the nonsmoking consumers attend bars, the share of nonsmoking groups attending restaurants is higher than their share in the population.

The share of nonsmoking bars in an equilibrium similar to Proposition 2 is determined by equating the expected profits of smoking and nonsmoking bars,

$$
\alpha\left(1+\frac{\Omega}{2}\right) V=\alpha\left(1+\frac{\Omega}{2}\right) v+\frac{(1-\alpha)(1+\Omega) v}{1-\gamma_{b}(1-\tau)},
$$

so that $\gamma_{b}^{*}=\frac{\alpha\left(1+\frac{\Omega}{2}\right)(V-v)-(1-\alpha)(1+\Omega) v}{(1-\tau) \alpha\left(1+\frac{\Omega}{2}\right)(V-v)}<\gamma_{r}^{*}$, with $\frac{\partial \gamma_{b}^{*}}{\partial \Omega}<0$. Because more smoking and mixed groups attend bars, the share of nonsmoking bars is lower and decreasing in the number of "good timers." It is not always the case that an equilibrium with a strictly positive share of nonsmoking bars $\gamma^{*}>0$ exists, even when the share of nonsmokers is high enough to satisfy a strictly positive share in Proposition (2), $\alpha>\frac{v}{V}$. Indeed, because of the increased number of mixed and smoking groups, the condition for some bars to supply a nonsmoking environment becomes

$$
\alpha\left(1+\frac{\Omega}{2}\right) V \geq\left(1+\Omega-\alpha \frac{\Omega}{2}\right) \nu
$$

which is equivalent to

$$
\alpha \geq \frac{v}{V} \frac{\left(1+\Omega-\alpha \frac{\Omega}{2}\right)}{\left(1+\frac{\Omega}{2}\right)}>\frac{v}{V} .
$$

Consider now the impact of a smoking ban affecting both bars and restaurants. ${ }^{11}$ I assume the smoking ban is credible and announced in $t=0$ before the entry decision of consumers in that

\footnotetext{
${ }^{11}$ Many smoking bans have been adopted first in restaurants, then in bars. In this framework this would even increase the specialization of bars, as nonsmokers would never attend them, and mixed groups are, at best $\left(i f \gamma_{b}^{*}=0\right)$, indifferent or prefer restaurants.
} 
period (and in particular the decision of "good timers"). As in Section 4.1, I assume the impact of a smoking ban to be an immediate shift to a state of the economy $\left\{p_{N S}=v, \gamma_{r}=\gamma_{b}=1\right\}$. The new state of the economy modifies the search strategy of new groups entering the market, as all groups of "good timers" are now indifferent between bars and restaurants.

The average profit of a restaurant just after a smoking ban $(t=0)$ is

$$
E\left(\pi_{r, t=0}\right)=(1-\tau)\left(1+\frac{\alpha \Omega}{2}\right) v+\tau\left(1+\frac{\Omega}{2}\right) v
$$

The average profit of a restaurant corresponds to the price $v$ paid by the remaining $(1-\tau)\left(\frac{\alpha \Omega}{2}\right)$ groups who were already on the market for restaurants, and by a first generation $\tau\left(1+\frac{\Omega}{2}\right)$ of groups in which "good-timers" are indifferent between bars and restaurants.

Similarly, the average profit of a bar becomes

$$
E\left(\pi_{b, t=0}\right)=(1-\tau)\left(1+\Omega-\frac{\alpha \Omega}{2}\right) v+\tau\left(1+\frac{\Omega}{2}\right) \nu
$$

If the supply of nonsmoking bars is zero before the ban, it has little direct impact on bars in the first period. However, demand evolves over time so that at every new period after the ban, all "good timers" are indifferent between bars and restaurants. The respective expected profits of restaurants and bars in period $t$ are

$$
E\left(\pi_{r, t}\right)=(1-\tau)^{t+1}\left(1+\frac{\alpha \Omega}{2}\right) v+\tau \sum_{i=0}^{t}(1-\tau)^{i}\left(1+\frac{\Omega}{2}\right) v
$$

and

$$
E\left(\pi_{b, t}\right)=(1-\tau)^{t+1}\left(1+\Omega-\frac{\alpha \Omega}{2}\right) v+\tau \sum_{i=0}^{t}(1-\tau)^{i}\left(1+\frac{\Omega}{2}\right) v
$$

Both average profits converge to $E(\pi)=\left(1+\frac{\Omega}{2}\right) v$ when $t \rightarrow \infty$. The long run expected profits in both submarkets are identical, but the initial point and the dynamic differ. When the ban is enacted, the number of customers in both submarkets starts to converge. Through time, the number of consumers going to bars decreases while the number of consumers going to restaurants increases.

The following example shows a pattern where a smoking ban hurts bars and does not affect restaurants in the long run. Assume the following parameters, $\alpha=0.5, \Omega=1, V=2, v=1, \tau=$ 




Figure 2: Smoking ban and expected profits: an example.

0.1 and $s$ sufficiently small. Assume also that, at the market equilibrium, some restaurants are nonsmoking $\left(\gamma_{r}^{*}>0\right)$. All "good timers" go to bars, and it is indeed an equilibrium strategy for some restaurant owners to ban smoking as

$$
\alpha\left(1+\frac{\Omega}{2}\right) V>\left(1+\alpha \frac{\Omega}{2}\right) v
$$

In bars, the equilibrium share of nonsmoking premises is zero, as no bars benefit from offering such an environment at a high price,

$$
\alpha\left(1+\frac{\Omega}{2}\right) V<\left(1+\Omega-\alpha \frac{\Omega}{2}\right) v
$$

Figure 2 presents the respective expected profits of bars and restaurants over time as described in (17) and (18), with a ban in $t=0$. In this case, the profit of restaurants slowly comes back to its initial value, but the profit of bars decreases. 


\section{Conclusion}

This paper studies the impact of group consumption on product diversity in a dynamic model of sequential search. I show that the presence of mixed groups creates a leverage effect of competition. This implies that new tastes may only be marginally represented in the market, even if they represent a large share of the population. I show that this result may explain the inability of the market to respond to the increased share of nonsmoking consumers by providing a large supply of nonsmoking environments. This is the reason why a smoking ban, even without considering its health consequences, may increase aggregate consumer welfare at the cost of decreasing the welfare of smokers.

Still, if smokers have sufficiently intense preferences for a smoking environment, a world without any smoking premises may not be an equilibrium without a strict enforcement. It may indeed be a profitable deviation for some firms to start offering smoking environments, specialized in smoking consumers. A limited provision of smoking premises does not necessary decrease aggregate surplus if search costs are sufficiently low. It does, however, constitute a transfer of surplus from consumers to restaurants, as the additional surplus of smoking consumers is extracted by those few smoking restaurants. A smoking ban completed by a policy of limited and expensive licenses redistributed among consumers may therefore be Pareto improving when smokers have very intense preferences. This feature arises only if all consumers and employees are perfectly informed utility maximizers, and the social cost of smoking is fully internalized within establishments. 


\section{Bibliography}

Adams, Scott and Chad D Cotti, "The effect of smoking bans on bars and restaurants: An analysis of changes in employment," The BE Journal of Economic Analysis \& Policy, 2007, 7 (1).

Adda, Jérôme, Samuel Berlinski, and Stephen Machin, "Market regulation and firm performance: the case of smoking bans in the United Kingdom," Journal of Law and Economics, 2012, 55 (2), 365-391.

Alamar, Benjamin C and Stanton A Glantz, "Smoke-free Ordinances Increase Restaurant Profit and Value," Contemporary economic policy, 2004, 22 (4), 520-525.

Allwright, Shane, "Republic of Ireland's indoor workplace smoking ban," British Journal of General Practice, 2004, 54 (508), 811-812.

Anderson, Simon $\mathbf{P}$ and Regis Renault, "Pricing, product diversity, and search costs: A Bertrand-Chamberlin-Diamond model,” The RAND Journal of Economics, 1999, pp. 719-735.

Bartosch, William J and Gregory C Pope, "Economic effect of restaurant smoking restrictions on restaurant business in Massachusetts, 1992 to 1998," Tobacco Control, 2002, 11 (suppl 2), ii38-ii42.

Besen, Stanley M and Joseph Farrell, "Choosing how to compete: Strategies and tactics in standardization,” The Journal of Economic Perspectives, 1994, pp. 117-131.

Borland, Ron, Hua-Hie Yong, Mohammad Siahpush, Andrew Hyland, Sharon Campbell, Gerard Hastings, K Michael Cummings, and Geoffrey T Fong, "Support for and reported compliance with smoke-free restaurants and bars by smokers in four countries: findings from the 
International Tobacco Control (ITC) Four Country Survey,” Tobacco control, 2006, 15 (suppl 3), iii34-iii41.

Boyes, William J and Michael L Marlow, "The public demand for smoking bans," Public Choice, 1996, 88 (1-2), 57-67.

Diamond, Peter A, “A model of price adjustment," Journal of Economic Theory, 1971, 3 (2), $156-168$.

Donni, Olivier and Pierre-André Chiappori, "Nonunitary models of household behavior: a survey of the literature," in "Household economic behaviors," Springer, 2011, pp. 1-40.

Dunham, John and Michael L Marlow, "Smoking laws and their differential effects on restaurants, bars, and taverns," Contemporary Economic Policy, 2000, 18 (3), 326-333.

_ and _ , "The economic incidence of smoking laws," Applied Economics, 2003, 35 (18), 19351942.

Fong, Geoffrey T, Andrew Hyland, Ron Borland, David Hammond, Gerard Hastings, Ann McNeill, Susan Anderson, K Michael Cummings, Shane Allwright, Maurice Mulcahy et al., "Reductions in tobacco smoke pollution and increases in support for smoke-free public places following the implementation of comprehensive smoke-free workplace legislation in the Republic of Ireland: findings from the ITC Ireland/UK Survey,” Tobacco control, 2006, 15 (suppl 3), iii51-iii58.

Gallus, Silvano, Piergiorgio Zuccaro, Paolo Colombo, Giovanni Apolone, Roberta Pacifici, Silvio Garattini, and C La Vecchia, "Effects of new smoking regulations in Italy," Annals of Oncology, 2006, 17 (2), 346-347.

Gersbach, Hans and Hans Haller, "Collective decisions and competitive markets," Review of Economic Studies, 2001, pp. 347-368.

_ and _, "Groups, collective decisions and markets," Journal of Economic Theory, 2011, 146 (1), 275-299.

Gilpin, EA, L Lee, and JP Pierce, "Changes in population attitudes about where smoking should not be allowed: California versus the rest of the USA," Tobacco Control, 2004, 13 (1), 38-44. 
Glantz, Stanton A and Lisa R Smith, "The effect of ordinances requiring smoke-free restaurants on restaurant sales.," American Journal of Public Health, 1994, 84 (7), 1081-1085.

Huang, P, AK De, and ME McCusker, "Impact of a smoking ban on restaurant and bar revenuesEl Paso, Texas, 2002.," MMWR: Morbidity \& Mortality Weekly Report, 2004, 53 (7), 150.

_, S Tobias, Kohout S Harris M, D Satterwhite, D M. Simpson, L Winn, J Foehner, and L Pedro, "Assessment of the impact of a 100\% smoke-free ordinance on restaurant sales-West Lake Hills, Texas, 1992-1994.," MMWR. Morbidity and mortality weekly report, 1995, 44 (19), 370.

Maskin, Eric and Jean Tirole, "Markov perfect equilibrium: I. Observable actions," Journal of Economic Theory, 2001, 100 (2), 191-219.

Phelps, Ryan, "The economic impact of 100\% smoking bans," Kentucky Annual Economic Report 2006, 2006, pp. 31-34.

Sciacca, John P and Michael I Ratliff, "Prohibiting smoking in restaurants: effects on restaurant sales," American Journal of Health Promotion, 1998, 12 (3), 176-184.

Wolinsky, Asher, "True monopolistic competition as a result of imperfect information," The Quarterly Journal of Economics, 1986, 101 (3), 493-511.

Yang, Huanxing, "Targeted search and the long tail effect," The RAND Journal of Economics, 2013. 


\section{Appendix: formal proofs}

\section{Proof of Lemma 1.}

A monopoly wants to maximize its profit and suffers no competition. As the marginal production cost is normalized to zero, I focus on strictly positive prices. For any price $p \leq v$, all consumers accept the offer and stay, regardless of the smoking policy. Hence, the per-period profit of the monopoly is

$$
\pi=p \tau\left(1+(1-\tau)+(1-\tau)^{2}+\ldots\right)=p
$$

Thus, conditional on serving all types of groups, the profit maximizing price is $p=v(\forall p \in(0, v])$. For any price $p^{\prime \prime}>V$, no customer accepts the offer and the profit is $0<v$. For any price $p^{\prime} \in$ $\left(\frac{v+V}{2}, V\right]$, if the restaurant allows smoking, only smoking groups accept the offer and stay, while other groups refuse the offer. The per-period profit is

$$
\pi^{\prime}=p^{\prime} \tau(1-\alpha-\mu)\left(1+(1-\tau)+(1-\tau)^{2}+\ldots\right)=(1-\alpha-\mu) p^{\prime}
$$

Thus, $\forall p^{\prime} \in\left(\frac{v+V}{2}, V\right]$, the profit maximizing price is $p^{\prime}=V$. Finally, the price $p^{\prime \prime} \in\left(v, \frac{v+V}{2}\right]$ that maximizes profit is $p^{\prime \prime}=\frac{v+V}{2}$. This implies that, if $(1-\alpha-\mu) V>\max \left\{v,(1-\alpha) \frac{v+V}{2}\right\}$, the profitmaximizing price of a monopoly is $p=V$. By banning smoking, the monopoly could indeed get at most $\alpha V<(1-\alpha-\mu) V$. Finally by serving all but the nonsmoking groups, it could get at most $\pi^{\prime \prime}=(1-\alpha) \frac{v+V}{2}<(1-\alpha-\mu) V$

Proof of Proposition 1. I study deviations from a market structure where all firms set a price $p_{s}=v$. Denote by $p_{-i}$ the price distribution where all firms but $i$ choose $p_{s}$. We know by the standard Diamond argument that setting $p_{i}^{\prime}<v$ is never a profitable deviation for a firm $i$. Since all groups already accept the offer and stay, and as firms are atomless so that no group will search for this specific firm, the per-period profit for any price $p_{i}^{\prime} \in(0, v]$ is at most $\pi\left(p_{i}^{\prime} \mid p_{-i}\right)=p_{i}^{\prime}$, maximum for $p_{i}^{\prime}=v$. I check under which conditions setting $p_{i}^{\prime}>v$ is a profitable deviation. I exclude prices strictly above $V$, as we already know by (2) that they yield zero demand. We also know by (2) that for any $p_{i}^{\prime}>v$, a restaurant focuses on smokers and mixed groups only, as it does not meet the participation constraint of a nonsmoking group. To receive a strictly positive profit, a deviating firm must either (i) set a price sufficiently low for smokers and mixed groups to prefer to come back 
than to search for another restaurant or, (ii) focus on one-time-only consumers, by just meeting the participation constraint of smokers, so that they consume once and search in the next period. The condition for (i) is to set a price $p^{\prime}$ such that smokers and mixed groups stay in the next period, which is

$$
\frac{V-p_{i}^{\prime}}{\tau} \geq \frac{V-v}{\tau}-s
$$

This rewrites

$$
p_{i}^{\prime} \leq v+s \tau
$$

By setting $p_{i}^{\prime}=v+s \tau$, the deviating firm gets a per period profit (with only smoker and mixed groups, all staying)

$$
\pi\left(p_{i}^{\prime} \mid p_{-i}\right)=(1-\alpha)(v+s \tau)
$$

This profit is lower than setting the same price as all other firms, $p_{i}=v$ if and only if $\pi\left(p_{i}^{\prime} \mid p_{-i}\right) \leq v$, which simplifies to

$$
s \leq \frac{\alpha \nu}{(1-\alpha) \tau}=s^{\prime}
$$

To meet condition (ii), it must be true that a firm setting $p_{i}^{\prime}=V$ decreases its profit. As long as search costs are not too high, this firm gets one-time-only consumers. As it meets the participation constraint of smokers, those accept the offer when matched with the high-price firm, but search for another one in the next period iff

$$
s \leq \frac{V-v}{\tau}=s^{\prime \prime}
$$

When $(1-\alpha) V>v$, it is always true that $s^{\prime \prime}>s^{\prime}$, so condition (27) is not binding whenever condition (26) is fulfilled. Thus, for $p=v$ to be an equilibrium when $s<s^{\prime}$, it must only be true that the profit with one-time-only consumers buying at price $V$ is lower than with returning 
customers at lower price, $\tau(1-\alpha) V \leq v$. This rewrites:

$$
\tau \leq \frac{v}{(1-\alpha) V}
$$

Proof of Proposition 2. I first show that the equilibrium exists. If the equilibrium exists, a share $\gamma^{*}$ of the firms plays a strategy $\left\{\sigma=N S, p_{N S}=V\right\}$, and a share $1-\gamma^{*}$ plays a strategy $\left\{\sigma=S, p_{S}=v\right\}$. Nonsmoking groups accept the offer from any restaurant and stay there, while all other groups refuse the nonsmoking offers and search for a smoking restaurant in the next period. In that case, the expected per period profit of a nonsmoking restaurant is given by

$$
\pi_{N S}=\tau\left(\alpha V+\alpha V(1-\tau)+\alpha V(1-\tau)^{2}+\ldots\right)=\alpha V
$$

the nonsmokers who find the restaurant by chance and then stay because it corresponds to their preferences and cannot find better on the market. The expected per-period profit of a smoking restaurant is given by

$$
\pi_{S}=\tau\left(\frac{v}{\tau}+\frac{v(1-\alpha) \gamma(1-\tau)}{\tau}+\frac{v(1-\alpha) \gamma^{2}(1-\tau)^{2}}{\tau}+\ldots\right)=\alpha v+\frac{(1-\alpha) v}{1-\gamma(1-\tau)}
$$

the sum of the nonsmoking consumers who find the restaurant by chance and stay, all the other consumers who find the restaurant by chance and stay, and all the consumers who first found a nonsmoking restaurant, and then searched. Equating the two expected profits (29) and (30) gives the equilibrium value of $\gamma^{*}=\frac{\alpha V-v}{(1-\tau) \alpha(V-v)}$. As the share of nonsmoking restaurants cannot be negative, if the share of nonsmoking groups is not sufficiently high $\alpha V \leq v$, the supply of nonsmoking premises is $\gamma^{*}=0$. This equilibrium is locally stable in the sense that best responses to any small perturbation to the equilibrium share of nonsmoking firms would bring this share back to equilibrium. Indeed, if $\gamma$ increases above $\gamma^{*}$, the profit of smoking firms becomes higher than the profit of nonsmoking ones, which gives an incentive to some additional firms to allow smoking (and set a price $p_{S}=v$ ). If consumers follow the assumed search pattern, smoking restaurants have no incentive to change their price (by the same argument as in Proposition 1, and as long as the conditions of existence in Proposition $1, s \leq \min \left\{\frac{\alpha v}{(1-\alpha) \tau}, \frac{(1-\alpha) v}{\alpha \tau}\right\}$ and $\tau \leq \min \left\{\frac{v}{(1-\alpha) V}, \frac{v}{\alpha V}\right\}$, are fulfilled). A nonsmoking restaurant could change its price to a value higher than $V$ and get 
zero profit. It could also try to meet the participation constraint of mixed groups, and set a price $p=\frac{V+v}{2}$. This would give a per period profit of

$$
\pi=\alpha \frac{V+v}{2}+\frac{\tau \mu}{1-\gamma(1-\tau)} \frac{V+v}{2}
$$

In this case, the nonsmokers stay in the restaurant but if the mixed groups search in the proposed equilibrium, they also search when a firm strictly meets their participation constraint. The profit in (31) is lower than $\pi_{N S}=\alpha V$ whenever

$$
\tau \leq \frac{\alpha(V-v)(1-\gamma)}{\mu(V+v)-\alpha \gamma(V-v)}
$$

Replacing $\gamma$ by its equilibrium value $\gamma^{*}$ therefore yields

$$
\tau \leq \frac{(1-\alpha) v}{\mu(v+V)}
$$

A nonsmoking restaurant would never benefit either from setting a price $p^{\prime}=v$, as it yields expected profit $\pi_{N S}=\left(\alpha+\frac{\mu}{1-\gamma(1-\tau)}\right) v<\pi_{S}$.

For this structure to be an equilibrium, groups must follow the assumed search behaviour. The search decision of groups is given by equations (4) and (5). As $u_{m}^{S}<u_{s}^{S}$, if mixed groups search for smoking restaurants, smoking groups also search. As mixed groups get zero surplus from nonsmoking restaurants (they do not consume there as $u_{m}^{N S}<0$ ), both mixed groups and groups of smokers search until they find a smoking restaurant whenever

$$
s \leq\left(1-\gamma^{*}\right) \frac{V+v}{2 \tau}
$$

Since, by definition, the nonsmokers do not search for another firm (because all restaurants give them identical surplus), the proposed structure is an equilibrium.

I then show that a sequence of best responses to an initial state of the world $\{\gamma=0, p s=v\}$ can only lead to the proposed equilibrium. When a firm $j$ has the possibility to revise its policy, it does so by choosing a strategy satisfying $\pi_{j}\left(p_{j}, \sigma_{j}, p_{S}, p_{N S}, \gamma\right)=\max _{p \geq 0, \sigma \in\{S, N S\}} \pi_{j}\left(p, \sigma, p_{S}, p_{N S}, \gamma\right)$. By Proposition 1 , we know that a firm $j$ choosing $\sigma_{j}=S$ maximizes $\pi_{j}\left(\gamma=0, p_{s}=v\right)$ by setting 
$p_{j}=v$. However, a firm can strictly increase its expected per-period profit by banning smoking if $\alpha V>v$. In that case, given consumers' search strategies it maximizes its profit by playing $\left\{p_{j}=V, \sigma_{j}=N S\right\}$, and getting profit $\pi_{j}=\alpha V>v$. The state of the world in the next period therefore becomes $\left\{p_{S}=v, p_{N S}=V, \gamma=\lambda\right\}$, with $\lambda$ being the share of firms allowed to revise their price and smoking policy at each period. Smoking restaurants can increase their profit by revising their strategy to $\{p=V, \sigma=N S\}$ a long as $\gamma<\gamma^{*}$, therefore leading to the proposed equilibrium.

\section{Proof of Proposition 3.}

- The ex ante expected surplus of nonsmoking groups is 0 . The expected surplus after the ban is therefore $E\left(U_{n s, b a n}\right)=\frac{V-v}{\tau}=\Delta_{n s}$.

- The ex ante expected surplus of mixed groups is

$$
\begin{aligned}
E\left(U_{m, \text { noban }}\right) & =(1-\gamma) \frac{V-v}{2 \tau}+\gamma(1-\tau)\left((1-\gamma) \frac{V-v}{2 \tau}-s\right) \\
& +\gamma^{2}(1-\tau)^{2}\left((1-\gamma) \frac{V-v}{2 \tau}-s\right)+\ldots \\
& =\frac{(1-\gamma) \frac{V-v}{2 \tau}-\gamma(1-\tau) s}{1-\gamma(1-\tau)}
\end{aligned}
$$

reflecting the fact that those groups buy only after finding a smoking restaurant. The expected surplus of those groups after the ban is

$$
E\left(U_{m, b a n}\right)=\frac{V-v}{2 \tau}
$$

thus the difference $\Delta_{m}$ is given by

$$
\begin{aligned}
\Delta_{m} & =E\left(U_{m, \text { ban }}\right)-E\left(U_{m, \text { noban }}\right) \\
& =\frac{\gamma(V-v+2(1-\tau) s)}{2(1-\gamma(1-\tau))} .
\end{aligned}
$$

In terms of $\alpha$, this rewrites by replacing $\gamma^{*}$ by its value

$$
\Delta_{m}=\frac{(V-v+2 s(1-\tau))(\alpha V-v)}{2 v(1-\alpha)(1-\tau)} .
$$


- Finally, the surplus of smoking groups after the ban is zero, but the surplus before the ban is not $\frac{V-v}{\tau}$, because those groups had to bear some search costs to find a good match. The surplus before the ban, equal the difference $\Delta_{s}$ is

$$
\Delta_{s}=\frac{(1-\gamma) \frac{V-v}{\tau}-\gamma(1-\tau) s}{1-\gamma(1-\tau)}
$$

In terms of $\alpha$, this rewrites by replacing $\gamma^{*}$ by its value

$$
\Delta_{s}=\frac{s \tau^{2}(\alpha V-v)-\tau\left(\alpha\left(s V+(V-v)^{2}\right)-s v\right)+(1-\alpha) v(V-v)}{(1-\alpha)(1-\tau) \tau v} .
$$




\section{For online publication: characterization of the equilibria of the game}

\section{Content:}

In this appendix, I characterize all possible equilibria, and check which ones satisfy the following criteria: (i) they hold when search costs become very low (i.e. $s \rightarrow 0$ ), (ii) they are stable in the sense that best responses to a small perturbation in $\gamma$ bring firms back to the proposed equilibrium, (iii) they are robust to advertising of the smoking policy of restaurants and (iv) they are robust to a (self-enforcing) coordinated deviation by a small share of restaurants.

I start by showing that prices must either correspond exactly to a "search constraint" (a price above which some groups prefer to search than to stay at the restaurant) or to a "participation constraint" (a price equal to the willingness to pay of some group). The first set of candidate equilibria corresponds to cases where both types of restaurants choose a search constraint. Two equilibria exist for some parameters, but none is stable, robust to small search costs or to advertising of the smoking policy. The second set of candidates are equilibria in which one firm chooses a participation constraint and the other a search constraint. Two equilibria exist for some parameters, but none is robust to small search costs or to advertising of the smoking policy. The third set of candidates are equilibria in which both firms choose a participation constraint. Six types of equilibria exist for some parameters ( $i) p_{s}=p_{n s}=V$ is not stable, not robust to a deviation by a share of restaurants, and not robust to advertisement of smoking policy, (ii) $\left\{p_{s}=v, p_{n s}=\frac{v+V}{2}\right\}$ (and the symmetric $\left\{p_{n s}=v, p_{s}=\frac{v+V}{2}\right\}$ ) is not robust to the advertisement of the smoking policy, (iii) $p_{s}=p_{n s}=v$ is not robust to small search costs or to the advertisement of the smoking policy, (iv) $\left\{p_{s}=V, p_{n s}=\frac{v+V}{2}\right\}$ and the symmetric $\left\{p_{n s}=V, p_{s}=\frac{v+V}{2}\right\}$ are not robust to a deviation by a small mass of restaurants when search costs are low. The two remaining types of equilibria satisfy all our criteria: ( $v)\left\{p_{n s}=V, p_{s}=v\right\},\left\{p_{s}=V, p_{n s}=v\right\}$ and (vi) $\left\{p_{s}=p_{n s}=\frac{v+V}{2}\right\}$.

Firms are atomless and consumers have to bear a linear search cost $s>0$ to try a different option. Hence, without product and consumer diversity, for a market price $p$, there exists an $\varepsilon>0$ such that a firm of type $i$ does not loose any profit by setting $p_{i}=p+\varepsilon$ as long as $p$ is below the monopoly price (Diamond, 1971). In the presence of product diversity, there are however two reasons for which a firm can loose demand from increasing price.

First, for each type of group $i \in\{s, m, n s\}$ and each type of smoking policy $\sigma_{j} \in\{S, N S\}$, there exist a price $p_{i}^{j}=v_{i}^{\sigma_{j}} \in\left\{v, \frac{v+V}{2}, V\right\}$ such that $u_{i}^{j} \geq 0, \forall p<p_{i}^{j}$. I denote $p_{i}^{j}$ as the "participation 
constraint" for a group of type $i$ in a firm of type $j, P C_{i}^{j}$. Hence, by condition (2) if a firm of type $j$ has strictly positive demand from groups of type $i$, increasing unilaterally the price from $p_{i}^{j}$ to any $p^{\prime}=p_{i}^{j}+\varepsilon$ with $\varepsilon>0$ discreetly decreases the demand for the firm.

Second, using (4) and (5), in a symmetric equilibrium, for each type of group $i$, there exists a price

$$
p_{i}^{S}=v_{i}^{S}-v_{i}^{N S}+p_{i}^{N S}+\frac{\tau S}{\gamma}
$$

such that $\forall p \leq p_{i}^{S}$, groups of type $i$ do not search for a nonsmoking restaurant when matched with a smoking restaurant setting price $p$ (as we are looking for symmetric equilibria where all firms of the same type set the same price, it is never the case that groups search for a firm of the same type in equilibrium). I denote this value of $p_{i}^{S}$ as the "search constraint" for a group of type $i$ in a firm of type $S, S C_{i}^{S}$. Similarly, there exists a price

$$
p_{i}^{N S}=v_{i}^{N S}-v_{i}^{S}+p_{i}^{S}+\frac{\tau s}{1-\gamma}
$$

such that $\forall p \leq p_{i}^{N S}$, groups of type $i$ do not search for a smoking restaurant when matched with a nonsmoking restaurant setting price $p$. I denote this value of $p_{i}^{N S}$ as the "search constraint" for a group of type $i$ in a firm of type $N S, S C_{i}^{N S}$.

Hence, if a firm of type $j \in\{S, N S\}$ has strictly positive demand from groups of type $i$, increasing unilaterally the price from $p_{i}^{j}=S C_{i}^{j}$ to any $p^{\prime}=p_{i}^{j}+\varepsilon$ with $\varepsilon>0$ discreetly decreases the demand for the firm.

I can thus restrict my attention to equilibrium prices corresponding to either a $P C$ or a $S C$. For each equilibrium, I first study whether it exists under at least some parameter value, provide the existence conditions, and check whether it survives my refinement criteria.

\section{I first study all possible equilibria where both types of firms choose a price corresponding} to a $S C$.

1. Both firms ensure $s$ don't search for the other type, $S C_{s}^{N S}$ and $S C_{s}^{S}$. In that case, firms set the 
highest price that satisfies respectively

$$
\begin{gathered}
V-p_{S} \geq v-p_{N S}+\frac{\tau s}{\gamma} \\
v-p_{N S} \geq V-p_{S}+\frac{\tau S}{1-\gamma} .
\end{gathered}
$$

Such an equilibrium would require $p_{N S}=p_{S}-(V-v)+\frac{\tau s}{\gamma}$ and $p_{S}=p_{N} S+(V-v)+\frac{\tau s}{1-\gamma}$, which is never true as it would require $\tau s=0$. The same applies when considering firms setting prices jointly satisfying $S C_{n s}^{N S}$ and $S C_{n s}^{S}$.

2. Firms of type $S$ ensure groups of type $m$ don't search, $S C_{m}^{S}$ and firms of type $N S$ ensure that groups of type $s$ don't search, $S C_{s}^{N S}$. The conditions on prices become

$$
\begin{aligned}
p_{N S} & =p_{S}-(V-v)+\frac{\tau s}{1-\gamma} \\
p_{S} & =p_{N S}+\frac{\tau s}{\gamma} .
\end{aligned}
$$

These functions do not cross, hence, it could be an equilibrium only if exactly $\gamma(1-\gamma)=$ $\frac{\tau s}{V-v}$. Hence, this is never the case when $s \rightarrow 0$. For higher values of $\mathrm{s}$, if $\gamma$ satisfies the condition, there is an infinite number of pairs $\left\{p_{S}, p_{N S}\right\}$ such that (45) and (46) are compatible, simply because the two functions are identical. For this to be an equilibrium, one would however need $\gamma$ to be the equilibrium share of $N S$ firms. Hence, expected profits must be identical. Given the assumed search behaviour, expected profits are given by

$$
\begin{aligned}
\pi_{S} & =(1-\alpha) p_{S} \\
\pi_{N S} & =\left((1-\alpha)+\frac{\alpha}{1-(1-\gamma)(1-\tau)}\right) p_{N S}
\end{aligned}
$$

Using $p_{S}=p_{N S}+\frac{\tau_{S}}{\gamma}, \pi_{S}=\pi_{N S}$ whenever

$$
\begin{aligned}
p_{N S} & =\frac{(1-\alpha) \tau_{S}(1-(1-\gamma)(1-\tau))}{\alpha \gamma} \\
p_{S} & =\frac{\tau s-(1-\alpha) \tau s(1-\gamma)(1-\tau)}{\alpha \gamma} .
\end{aligned}
$$

However, the proposed equilibrium structure is not stable in the sense that for any small perturbation in $\gamma$ the best responses of firms allowed to modify their price and smoking 
policies do not converge to the assumed equilibrium. Indeed, if $\gamma$ is slightly above one of the two values satisfying $\gamma(1-\gamma)=\frac{\tau s}{V-v}$ (if such values exists), $p_{N S}$ should increase more than $p_{S}$ by (45) and (46). Therefore, $\gamma$ must also increase for profits to remain equal. The same reasoning applies to the case where prices are determined to satisfy $S C_{m}^{N S}$ and $S C_{n s}^{s}$.

Finally, the proposed equilibrium is not robust to advertisement of smoking policy. For mixed groups to search within both categories of restaurants, they need to be indifferent ex-ante, this is $p_{S}=p_{N S}$, while here $p s>p_{N S}$. Hence, $S C_{m}^{S}$ is never binding in the presence of advertisement of smoking policy.

3. Firms of type $S$ ensure groups of type $n s$ don't search, and firms of type $N S$ ensure groups of type $s$ don't search, $S C_{n s}^{S}$ and $S C_{s}^{N S}$. This would imply that no group searches. The corresponding prices are

$$
\begin{gathered}
p_{N S}=p_{S}-(V-v)+\frac{\tau S}{1-\gamma} \\
p_{S}=p_{N S}-(V-v)+\frac{\tau S}{\gamma} .
\end{gathered}
$$

The two are equal whenever $\gamma(1-\gamma)=\frac{\tau s}{2(V-v)}$. Hence, this is never the case when $s \rightarrow 0$. For this to be an equilibrium, one would however need $\gamma$ to be the equilibrium share of $N S$ firms. Hence, expected profits must be identical. In this case, as no group searches, this corresponds to $\gamma=\frac{1}{2}$. However, this is not stable in the sense that for any small modification of $\gamma$ there is no sequence of best responses converging to the equilibrium (if $\gamma$ increases, $p_{N S}$ increases and $p_{S}$ decreases, hence choosing $N S$ is more profitable, and $\gamma$ increases).

Finally, the proposed equilibrium is not robust to the advertisement of the smoking policy. For $S C_{s}^{N S}$ and $S C_{n s}^{S}$ to jointly hold, it must be the case that $u_{s}^{S}>u_{s}^{N S}$ and $u_{n s}^{N S}>u_{n s}^{S}$. In that case, smoking groups prefer to search only among smoking restaurants and nonsmoking groups only among nonsmoking restaurants.

4. When both types of firms ensure groups of type $m$ don't search, $S C_{m}^{S}$ and $S C_{m}^{N S}$, the corre- 
sponding prices are

$$
\begin{gathered}
p_{N S}=p_{S}+\frac{\tau s}{1-\gamma} \\
p_{S}=p_{N S}+\frac{\tau s}{\gamma}
\end{gathered}
$$

which impossible as it would require $\tau s=0$.

5. When the conditions are $S C_{m}^{S}$ and $S C_{n s}^{N S}$, one would need both

$$
\begin{aligned}
p_{S} & =p_{N S}+\frac{\tau s}{\gamma} \\
p_{N S} & =p_{S}+(V-v)+\frac{\tau s}{1-\gamma},
\end{aligned}
$$

which is impossible as $V-v>0$.

6. When the conditions are $S C_{s}^{S}$ and $S C_{n s}^{N S}$, one would need both

$$
\begin{gathered}
p_{S}=p_{N S}+(V-v)+\frac{\tau s}{\gamma} \\
p_{N S}=p_{S}+(V-v)+\frac{\tau S}{1-\gamma},
\end{gathered}
$$

which is impossible as $V-v>0$.

I then study all possible equilibria where one type of firm chooses a PC, and the other a SC

I assume firms of type $N S$ choose a PC (an identical exercise can be made with $S$ choosing a $\mathrm{PC})$.

1. Firms of type $N S$ set $p_{N S}=V$. As $u_{i}^{N S} \leq 0, \forall i \in\{s, m, n s\}$, no group ever prefers to bear a strictly positive search cost in order to search for a firm of type $N S$ and no SC is ever binding.

2. Firms of type $N S$ set $p_{N S}=\frac{v+V}{2}$. The only possibly binding $S C$ is thus $S C_{n s}^{S}$, to ensure 
consumers of type $n s$ don't search for $N S$. This implies

$$
\begin{aligned}
p_{S} & =p_{N S}-(V-v)+\frac{\tau s}{\gamma} \\
& =\frac{3 v-V}{2}+\frac{\tau s}{\gamma}
\end{aligned}
$$

It should also be the case that $p_{S} \leq v$. In order to have strictly positive demand from groups of type $n s$. Hence, $\frac{3 v-V}{2}+\frac{\tau s}{\gamma} \leq v$,

$$
\gamma \geq \frac{2 \tau s}{V-v}
$$

If groups of type $m$ search for $S$, the proposed structure cannot be an equilibrium, as setting price $p_{N S}=\frac{v+V}{2}$ does not correspond to a $P C$ anymore (mixed groups would not be part of the demand of NS firms). This condition corresponds to

$$
0 \geq \frac{V+v}{2}-p_{S}-\frac{\tau_{S}}{1-\gamma}
$$

This simplifies to $\gamma(1-\gamma) \leq \frac{\tau s}{V-v}$, hence, this is never the case when $s \rightarrow 0$. For the two conditions to hold at the same time it should be the case that the equilibrium share of nonsmoking restaurants satisfies $\frac{2 \tau s}{V-v} \leq \frac{\tau s}{(V-v)(1-\gamma)}$, hence, $\gamma \geq \frac{1}{2}$.

Finally, the proposed equilibrium is not robust to the advertisement of the smoking policy. For mixed groups to search within both categories of restaurants, they need to be indifferent ex-ante, this is $p_{S}=p_{N S}$.

3. Firms of type $N S$ set $p_{N S}=v$. It is only a PC of groups with strictly positive demand for firms of type $N S$ if groups of all types consume in NS. If firms of type $S$ choose a SC, it cannot be $S C_{s}^{S}$ to avoid $s$ to search for $N S$, as they anyway never do $\left(u_{s}^{N S}=0\right)$. It cannot be either $S C_{n s}^{S}$ to avoid $n s$ to search for $N S$ as it would imply identical demand for both types of firms, and therefore lower profit for $S$ as $p_{S}$ should be equal to $p_{S}=p_{N S}-(V-v)-\frac{\tau S}{\gamma}$, with $p_{S}<p_{N S}$. The only remaining possibility is thus $S C_{m}^{S}$ such that groups of type $m$ don't 
search, this is

$$
\begin{aligned}
p_{S} & =p_{N S}+\frac{\tau s}{\gamma} \\
& =v+\frac{\tau s}{\gamma}
\end{aligned}
$$

However, at the same time consumers of type $s$ must still not search,

$$
V-v-\frac{\tau s}{\gamma}-\frac{\tau}{1-\gamma}<0
$$

thus $\gamma(1-\gamma) \leq \frac{\tau s}{V-v}$. Hence, this is never the case when $s \rightarrow 0$.

Finally, the proposed equilibrium is not robust to advertisement of smoking policy. For mixed groups to search within both categories of restaurants, they need to be indifferent ex-ante, this is never the case here as $p_{S}>p_{N S}$, hence $u_{m}^{S}<u_{m}^{N S}$.

\section{Finally, I study all possible equilibria where both type of firms choose a PC}

1. Both types of firms set a high price, $p_{S}=p_{N S}=V$. As $u_{i}^{j} \leq 0, \forall i, j$, no consumer ever search. Groups of smokers only buy if matched with a smoking restaurant, and never search. Mixed groups never buy as $u_{m}^{j}<0, \forall j \in\{S, N S\}$. Groups of nonsmokers only buy if matched with a nonsmoking restaurant, and never search. In that case, expected profits are

$$
\begin{aligned}
\pi_{N S} & =\alpha V \\
\pi_{S} & =(1-\alpha-\mu) V .
\end{aligned}
$$

Unless exactly $\alpha=(1-\alpha-\mu)$, there is no value of $\gamma \in(0,1)$ such that the two expected profits are equal. For all other values of $\alpha$, the equilibrium is the "Diamond" one studied in the main part of the paper, not robust to a deviation by a share of restaurants (see equation (7)), and not to robust to advertisement of smoking policy.

2. If $p_{s}=v$ and $p_{n s}=\frac{v+V}{2}$. For it to be an equilibrium, it needs to either be the case that groups 
of type $m$ do not search when matched with a firm of type $N S$. This is the case when

$$
\begin{aligned}
& \frac{v+V}{2}-v \leq \frac{\tau s}{1-\gamma} \\
& \Leftrightarrow \frac{V-v}{2} \leq \frac{\tau s}{1-\gamma}
\end{aligned}
$$

Hence, this is never the case when $s \rightarrow 0$. Alternatively, if type $m$ search, the equilibrium exists for $\tau$ sufficiently high. The equilibrium is not robust to advertisement of the smoking policy. Given the price structure, $u_{m}^{S}>u_{m}^{N S}$, so mixed groups never go to nonsmoking restaurants.

A symmetric result holds for $p_{n s}=v$ and $p_{s}=\frac{v+V}{2}$.

3. If $p_{s}=v$ and $p_{n s}=v$, smokers search whenever

$$
V-v \geq \frac{\tau s}{1-\gamma}
$$

and nonsmokers search whenever

$$
V-v \geq \frac{\tau s}{\gamma}
$$

hence at least one type of consumer search when $s \rightarrow 0$, and the proposed structure cannot hold in equilibrium. It is also not robust to advertisement of the smoking policy. Given the price structure, $u_{s}^{S}>u_{s}^{N S}$, and $u_{n s}^{N S}>u_{n s}^{S}$ so that smokers never search for nonsmoking restaurants and nonsmokers never search for smoking restaurants.

4. If $p_{s}=\frac{v+V}{2}$ and $p_{n s}=V$, groups of type $s$ search until they find a $S$ restaurant iff

$$
\frac{V-v}{2} \geq \frac{\tau s}{1-\gamma}
$$

which always holds $\forall \gamma \in(0,1)$ when $s \rightarrow 0$. Groups of type $n s$ buy only when randomly matched with a $N S$ firm, and never search, and $m$ buy only when randomly matched with a 
$S$ firm, and never search. Expected profits are therefore

$$
\begin{aligned}
\pi_{S} & =\left(\mu+\frac{1-\alpha-\mu}{1-\gamma(1-\tau)}\right) \frac{v+V}{2} \\
\pi_{N S} & =\alpha V
\end{aligned}
$$

Hence, in such an equilibrium $\gamma=\frac{\alpha(3 V+v)-(v+V)}{(1-\tau)(2 \alpha V-\mu(v+V))}$.

The proposed equilibrium is stable in the sense that for any small perturbation $\gamma^{\prime}>\gamma$, it is a best response for some restaurants to switch from $N S$ to $S$. However, for values of $s \rightarrow 0$, it is enough to have a small share $\lambda$ of firms of type $s$ to set price $v$ for the equilibrium not to hold. Indeed, smokers start searching for these firms and nonsmokers start buying from these firms, who thus make profit

$$
\pi_{S}^{\prime}=\left(\alpha+\mu+\frac{1-\alpha-\mu}{1-\lambda(1-\tau)}\right) \frac{v+V}{2}
$$

with $\pi_{S}^{\prime}>\alpha V$ for $\lambda$ sufficiently small. A price $p_{S}=v$ is the best response for smoking firms, as for any price strictly above $v$ they lose demand from nonsmokers.

It is also robust to advertising, for any $c>0$, only smokers choose to search within $S$ restaurants only, while the others are only consuming when randomly matched.

5. If $p_{s}=v$ and $p_{n s}=V$. This equilibrium is the one studied in the main part of the paper and its existence is shown in Proposition 2.

This equilibrium is robust to advertisement of the smoking policy. Given the price structure, $u_{s}^{S}>u_{s}^{N S}, u_{m}^{S}>u_{m}^{N S}$ and $u_{n s}^{S}=u_{n s}^{N S}$. Hence, smokers and mixed groups are willing to pay a small cost $c$ to search only among smoking restaurants, and nonsmokers are indifferent between the two and are not willing to pay any search cost. The expected profits under advertisement are

$$
\begin{aligned}
\pi_{n s} & =\alpha V \\
\pi_{s} & =\left(\frac{1-\alpha}{1-\gamma}+\alpha\right) v
\end{aligned}
$$


The equilibrium share of non-smoking restaurants therefore solves $\gamma^{\prime}=\frac{\alpha V-v}{\alpha(V-v)}$. The share $\gamma^{*}=\frac{\alpha V-v}{\alpha(1-\tau)(V-v)} \geq \gamma^{\prime}$ in the absence of advertising converges to $\gamma^{\prime}$ when groups survive for sufficiently long $\tau \rightarrow 0$.

Firms have even fewer incentives to deviate in the presence of advertising, as a nonsmoking restaurant, by decreasing its price, cannot gain a single consumer (because all consumers but nonsmoking groups search only among smoking restaurants). By increasing their price, smoking restaurants lose their demand from nonsmoking groups, as in the case without advertising.

A symmetric result holds with $p_{s}=V$ and $p_{n s}=v$, with $\tilde{\gamma}=1-\frac{(1-\alpha-\mu) V-v}{(1-\alpha-\mu)(V-v)}$.

6. $p_{s}=\frac{v+V}{2}$ and $p_{n s}=\frac{v+V}{2}$, both $s$ and $n s$ search, and $m$ accept any offer whenever

$$
\begin{aligned}
\frac{V-v}{2} \geq \frac{\tau s}{1-\gamma} \\
\frac{V-v}{2} \geq \frac{\tau s}{\gamma} .
\end{aligned}
$$

This is always the case when $s \rightarrow 0$. The equilibrium share of nonsmoking restaurant is the one that equates both expected profit, this is

$$
\begin{aligned}
\pi_{N S} & =\left(\frac{\alpha}{1-(1-\gamma)(1-\tau)}+\mu\right) \frac{v+V}{2} \\
\pi_{S} & =\left(\frac{1-\alpha-\mu}{1-\gamma(1-\tau)}+\mu\right) \frac{v+V}{2}
\end{aligned}
$$

so that $\gamma=\frac{\alpha-\tau(1-\alpha-\mu)}{(1-\mu)(1-\tau)}$.

This equilibrium features shares of smoking and nonsmoking restaurants much closer to the tastes of consumers, and identical to the prevalence of smoking when $\tau \rightarrow 0$. The proposed equilibrium is stable in the sense that for any small perturbation $\gamma^{\prime}>\gamma$, it is a best response for some restaurants to switch from $N S$ to $S$. It is also robust to advertisement, with equilibrium share of nonsmoking restaurants $\gamma^{\prime}=\frac{\alpha}{1-\mu}$, where groups of nonsmokers search only for nonsmoking restaurants $u_{n s}^{N S}>u_{n s}^{S}$, smoking groups search only for smoking restaurants, $u_{s}^{S}>u_{s}^{N S}$, and mixed groups do not choose a specific subset of restaurants as $u_{m}^{S}=u_{m}^{N S}$. 